\title{
The brain subcortical white matter and aging A quantitative fractional anisotropy analysis
}

\author{
Eliasz Engelhardt ${ }^{1}$, Denise Madeira Moreira ${ }^{2,3}$, Jerson Laks ${ }^{4,5}$
}

\begin{abstract}
To study the integrity of hemispheric subcortical white matter by comparing normal young and elderly subjects using quantitative fractional anisotropy (DTI-FA). Methods: Subjects of two different age groups (young=12, elderly=12) were included. MR - GE Signa Horizon - 1.5T scans were performed. Cases with Fazekas scores $\leq 3$ were assessed on FLAIR sequence. Standard parameters for DTI-FA were used. ROIs were placed at various sites of the subcortical white matter, and the genu and splenium of the midline corpus callosum. Analysis was performed using Functool. Statistics for anterior and posterior white matter, as well as the genu and splenium were compared between the groups. The study was approved by the Ethics Committee of IPUB-UFRJ and informed consent obtained. Results: DTI-FA showed lower anisotropy values in the anterior region (subcortical white matter and genu), but not in the posterior region (subcortical white matter and splenium), in elderly normal subjects compared to young subjects. Conclusion: The results may represent loss of integrity of anterior (frontal) white matter fibers in the elderly subjects. These fibers constitute important intra- and inter-hemispheric tracts, components of neural networks that provide cognitive, behavioral, motor and sensory integration. The loss of integrity of the anterior segments of the studied fiber systems with ageing, represents a disconnection process that may underlie clinical manifestations found in elderly subjects such as executive dysfunction.
\end{abstract}

Key words: white matter, corpus callosum, fractional anisotropy, aging.

\section{Substância branca cerebral e envelhecimento: análise com anisotropia fracionada quantitativa}

Resumo - Estudar a integridade da substância branca hemisférica subcortical, comparando sujeitos normais jovens e idosos, com anisotropia fracionada quantitativa (DTI-FA). Métodos: Foram incluídos sujeitos de dois grupos etários (jovem=12, idoso=12). Obtidas imagens de MR - GE Signa Horizon - 1.5T. Escore de Fazekas $\leq 3$ avaliado na sequência em FLAIR. Utilizados parâmetros padrão para DTI-FA. ROIs colocados em locais variados da substância branca subcortical, e no joelho e esplênio do corpo caloso na linha média. Análise com Functool. Estatística para comparar a substância branca anterior e posterior entre os grupos. Aprovado pela Comissão de Ética do IPUB-UFRJ, consentimento informado obtido. Resultados: DTI-FA mostrou redução dos valores de anisotropia na região anterior (substância branca subcortical e joelho), porém não na região posterior (substância branca subcortical e esplênio), nos sujeitos normais idosos em comparação aos jovens. Conclusão: Os resultados podem ser considerados como representando perda da integridade das fibras da substância branca anterior (frontal) no sujeitos do grupo idoso. Tais fibras constituem os importantes feixes intra- e inter-hemisféricos, componentes de redes neurais relacionadas com integração cognitiva, comportamental, motora e sensorial. A perda da integridade com o envelhecimento dos segmentos anteriores dos sistemas de fibras estudados representa um processo de desconexão que pode estar subjacente a manifestações clínicas, como a disfunção executiva, eventualmente encontradas em sujeitos idosos.

Palavras-chave: substância branca, corpo caloso, anisotropia fracionada, envelhecimento.

\footnotetext{
${ }^{1}$ Coordinator, Cognitive and Behavioral Neurology Unit - INDC/UFRJ, Rio de Janeiro RJ, Brazil. ${ }^{2}$ Coordinator, Neuroimaging Unit - INDC/UFRJ, Rio de Janeiro RJ, Brazil. ${ }^{3}$ Radiologist, Pró-Cardíaco Hospital/RJ. ${ }^{4}$ Coordinator, Center for Alzheimer's Disease - CDA-IPUB/UFRJ. ${ }^{5}$ Medical Sciences Faculty, UERJ, Rio de Janeiro RJ, Brazil.
}

Eliasz Engelhardt - Av. Nossa Senhora de Copacabana 749/708 - 22050-000 Rio de Janeiro RJ - Brazil. E-mail: eliasz@centroin.com.br

Disclosure: The authors report no conflicts of interest.

Received May 21, 2009. Accepted in final form August 06, 2009. 
The subcortical white matter makes up around half of the human brain volume. It is responsible for the interconnection of cortical and subcortical areas, participating in the constitution of the wide neural networks related to a host of motor, sensory, cognitive, and behavioral functions. This white matter is composed of fiber bundles which are classified as projection, associative and commissural tracts. The main projection systems are constituted by the cortico-bulbar, cortico-spinal, and cortico-pontine fibers. The associative bundles include the superior and inferior longitudinal tracts, the superior and inferior occipito-frontal tracts, and the limbic uncinate fascicle, cingulum, and fornix while commissural fibers constitute the large corpus callosum and the anterior comissure. These tracts of fibers spread out anteriorly, posteriorly, and laterally, where they intermingle in the centrum semiovale and with the fibers of the corona radiata. ${ }^{1-3}$

Structural imaging techniques (computer tomography and magnetic resonance) reveal the subcortical white matter in a clear yet homogeneous way. ${ }^{4-7}$ The recently developed diffusion tensor imaging (DTI) technique offers a new opportunity to evaluate the brain white matter architecture in a qualitative and quantitative manner, both in normal and pathological states. A detailed analysis of the white matter with DTI is possible given two of its features - mean diffusivity and the fractional anisotropy (FA). Currently, the most widely used measure of anisotropy is DTIFA that allows quantification, where the values obtained represent an average of the sampled fibers in a given region of interest (ROI). It is a highly sensitive but fairly nonspecific biomarker of neuropathology and microstructural architecture of white matter and is generally considered a marker of its integrity. ${ }^{8-9}$ Several studies demonstrated that the organization of white matter fiber bundles is the basis for DTI-FA. The myelin appears to influence its measures, as well as axonal damage and loss. The parallel organization of white matter fiber bundles is the basis for anisotropic diffusion, whereas myelin appears to modulate the amount of anisotropy. ${ }^{8}$ DTI-FA appears to be the most sensitive imaging parameter to determine age-related white matter damage, and the strong relationship of such damage with this parameter suggests that axonal damage may be important in age-related cognitive decline. ${ }^{10}$

Analysis of lesions identified by neuroimaging and verified neuropathologically has shown that low DTI-FA values are indicative of axonal damage and demyelination. ${ }^{8-9}$ However, analysis of regions visually identified as unaffected, may also show similar derangement of the microarchitecture of the white matter. ${ }^{11-12}$ Changes may also be seen upon comparing brains of younger with older subjects, showing the effect of age on white matter. ${ }^{5-6}$
The objective of this study was to describe the subcortical white matter in normal subjects by comparing a young group with an elderly group of subjects using quantitative fractional anisotropy (DTI-FA). The relevance of such a study lies in the evaluation of structural age-related changes, which may provide a better understanding of pathophysiological aspects of possible age-related cognitive changes. In addition, such quantitative structural agerelated change analysis in normal subjects may serve as a reference standard against which individuals with neuropathological disorders may be compared.

\section{Methods \\ Subjects}

The present study included two samples of normal subjects, one young group and one elderly group. The rationale for the choice of the groups was based on structural and cognitive data, as well as on clinical aspects. The longitudinal volumetric assessments showed a declining curve beginning around the age of 30 progressing clearly after the age of 60 years. ${ }^{13}$ Longitudinal cognitive evaluation demonstrated that age-related cognitive decline begins in healthy young adults at around the age of 30 years, and proceeds in several aspects thereafter. ${ }^{14}$ In the clinical setting, the 30-year-old age bracket is considered paradigmatic for comparisons in studies on cognitive decline. ${ }^{15}$ The subjects included in this investigation had no cognitive or behavioral complaints at the time of the evaluation. The characteristics of the samples are shown in Table 1.

\section{Techniques}

A standard series of MR scans of the brain, complemented with DTI acquisitions, was obtained for the two

Table 1. Characteristics of the samples.

\begin{tabular}{lcc}
\hline & Young & Elderly \\
\hline $\mathrm{N}$ & 12 & 12 \\
Sex $(\mathrm{M} / \mathrm{F})$ & $4 / 8$ & $5 / 7$ \\
Age (years) & $30.6 \pm 5.7$ & $74.8 \pm 5.1$ \\
$\quad($ range) & $(24-40)$ & $(66-82)$ \\
Education (years: Mean $\pm \mathrm{SD})$ & $12.5 \pm 3.71$ & $12.4 \pm 2.43$ \\
MMSE $^{\mathrm{a}}$ (score: Mean $\left.\pm \mathrm{SD}\right)$ & $28.8 \pm 1.11$ & $27.4 \pm 2.70$ \\
CDR $^{\mathrm{b}}$ (score) & 0 & 0 \\
Hachinskic $^{\mathrm{c}}$ (score) & $0.17 \pm 0.58$ & $0.92 \pm 0.79$ \\
Fazekas $^{\mathrm{d}}$ (score) & $0.17 \pm 0.39$ & $2.0 \pm 0.85$ \\
\hline
\end{tabular}

${ }^{a}$ MMSE, Mini-Mental State Examination (short cognitive screening tool) ${ }^{16}$; ${ }^{b} \mathrm{CDR}$, Clinical Dementia Rating scale (global severity stages from 0 to 3 ) $^{17}$; ${ }^{c}$ Hachinski, ischemic score (clinical assessment of vascular risk $)^{18}$; ${ }^{\mathrm{A}}$ Fazekas, white matter lesion scale (severity from 0 to 6$)^{19}$. 


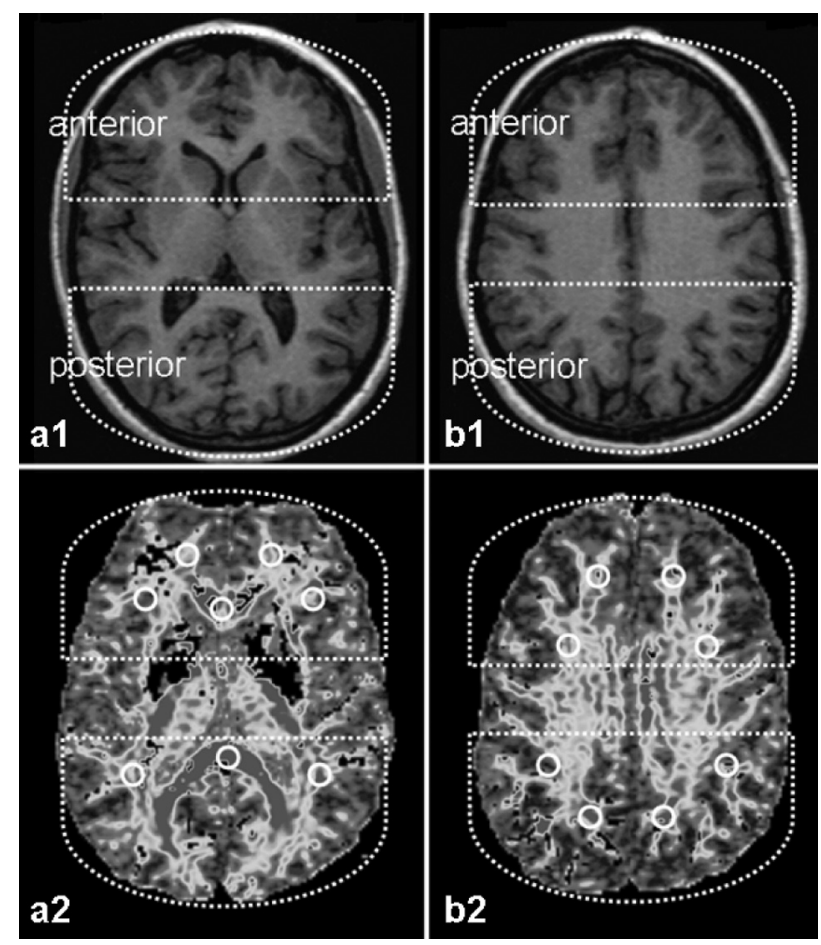

Figure. MR scans (axial sections at basal ganglia and supracallosal levels) in 3DT1 sequence (a1 and b1) for topographical reference, and DTI-FA maps at the same levels ( $a 2$ and b2) (in black and white). The ROIs are shown in the DTI-FA maps, localized in the subcortical white matter (anterior and posterior regions circumscribed by broken lines), and corpus callosum (genu and splenium).

samples on a 1.5T GE Signa Horizon device. Axial plane fluid-attenuated inversion recovery (FLAIR) sequence scans were examined to evaluate the presence of white matter lesions, which were classified according to Fazekas's scoring system. ${ }^{19}$ Only cases with score $\leq 3$ (visual assessment) were included. The scoring was performed by two of the authors (DMM and EE) in consensus.

The parameters for the DTI-FA acquisition employed in the present study were as follows: TR/TE $=10000 / 89.1$ msec, matrix $=128 \times 128, \mathrm{FOV}=30 \times 24 \mathrm{~mm}, \mathrm{NEX}=1, b=1000$ $\mathrm{sec} / \mathrm{mm}^{2}$, slice thickness $=5 \mathrm{~mm}$, number of slices $=30$ without gap, being in-line with values found in international studies on the theme.

Circular ROIs of $60 \mathrm{~mm}^{2}$ were placed at 14 symmetrical regions of both hemispheres on two axial planes (basal ganglia and supracallosal levels, parallel to the AC-PC line) of the DTI-FA maps (total number of ROIs $=168$ for each group). For statistical analysis, the ROIs were divided into anterior (frontal) and posterior (temporo-parietooccipital) regions. It should be noted that the anterior and posterior groups of ROIs were positioned to measure the intermingled fibers of the anterior segments of the inferior and superior occipito-frontal tracts and uncinate fascicle, the superior longitudinal tract, besides other fibers of the anterior corona radiata, and also the lateral spread of the anterior segment of the corpus callosum, and to measure posterior segments of the inferior occipito-frontal and inferior and superior longitudinal tracts, besides other fibers of the superior and posterior corona radiata, as well as the lateral spread of the posterior segment of the corpus callosum. Additionally, ROIs were placed on the genu and the splenium of the midline corpus callosum on one axial plane (basal ganglia level, parallel to the AC-PC line) of the DTI-FA maps (total number of ROIs=24 for each group), where callosal fibers alone could be evaluated ${ }^{1,20}$ (Figure).

The DTI-FA maps were analyzed on an ADW 4.3 Work Station using the Functool 4.5.3 (GE Medical Systems). The averaged values of the subcortical white matter ROIs were pooled for anterior (frontal) and posterior (temporo-parieto-occipital) regions, and the corpus callosum ROIs into genu and splenium sites. Statistical analysis ${ }^{21}$ was performed to compare intra-sample and inter-sample values of anterior and posterior regions of the subcortical white matter, and of genu and splenium of the corpus callosum. Basic statistics were applied, and mean \pm sd calculated for the anterior and posterior groups of values of the subcortical white matter, and the same for the genu and splenium of the corpus callosum of each sample. Student's t test was used to assess statistical differences between the studied regions.

\section{Ethics}

The present study is part of a larger project on Vascular Cognitive Disorder, approved by the Ethics Committee of IPUB-UFRJ. Informed consent was obtained from the participants before they embarked on the study.

\section{Results}

The DTI-FA data on subcortical white matter and the corpus callosum of the young and old groups are depicted in Table 2.

The anterior region of the subcortical white matter in the elderly showed significantly reduced DTI-FA values in comparison to the young group (inter-sample), but no difference between values of the posterior regions. Significantly lower values were observed in the anterior white matter compared to the posterior region in both groups, although this difference was more significant in the elderly (intra-sample). The DTI-FA values for the genu, but not the splenium, were significantly lower in the elderly in comparison to the young group (inter-sample). Values for the genu were found to be significantly lower than those for the splenium in the elderly group, but not the young group (intra-sample). 
Table 2. Subcortical white matter and corpus callosum. Results of quantitative FA in young vs. elderly.

\begin{tabular}{|c|c|c|c|c|}
\hline \multirow[b]{2}{*}{ Regions } & \multirow{2}{*}{$\begin{array}{c}\text { ROIs } \\
\text { n per group }\end{array}$} & \multicolumn{2}{|c|}{$\begin{array}{c}\text { FA units } \\
(\text { mean } \pm \text { sd })\end{array}$} & \multirow[b]{2}{*}{ p-value } \\
\hline & & Young group & Elderly group & \\
\hline \multicolumn{5}{|c|}{ Subcortical white matter } \\
\hline Anterior ${ }^{*}$ & 96 & $0.3629 \pm 0.09$ & $0.3122 \pm 0.05$ & 0.0001 \\
\hline Posterior ${ }^{\star *}$ & 72 & $0.3997 \pm 0.07$ & $0.3937 \pm 0.09$ & 0.6559 \\
\hline p-value & - & 0.0045 & 0.0001 & - \\
\hline \multicolumn{5}{|c|}{ Corpus callosum } \\
\hline Genu & 12 & $0.6861 \pm 0.08$ & $0.6041 \pm 0.05$ & 0.0064 \\
\hline Splenium & 12 & $0.7397 \pm 0.06$ & $0.7230 \pm 0.04$ & 0.4310 \\
\hline p-value & - & 0.1150 & 0.0001 & - \\
\hline
\end{tabular}

${ }^{*}$ frontal; ${ }^{* *}$ temporo-parieto-occipital; ${ }^{\ddagger}$ Student p-value.

In sum, the inter-sample comparison of the anisotropy values showed significantly lower values in the elderly than the young group for anterior subcortical white matter and the genu, but not between the values of the posterior white matter and the splenium. The intra-sample comparison revealed significantly lower values for the anterior subcortical white matter in relation to the posterior in both groups, reaching greater significance in the elderly. For the corpus callosum, the anisotropy values of the genu in comparison to the splenium were significantly reduced in the elderly, but not in the young group.

\section{Discussion}

The present data showed changes in DTI-FA values between young and elderly groups, both in subcortical white matter (anterior [frontal] and posterior [temporo-occipitoparietal] regions), and midline corpus callosum (anterior [genu] and posterior [splenium] segments).

The inter-sample measures of the anterior subcortical white matter (represented by anterior segments of several anteroposterior tracts, subcortico-cortical fibers, and the lateral spread of the corpus callosum, as well as of the genu), showed significantly lower anisotropy in the elderly compared to the young group. This reduction was not observed in relation to the posterior subcortical white matter (represented by posterior segments of several anteroposterior tracts, subcortico-cortical fibers, and the lateral spread of the corpus callosum, and the splenium). On intra-sample data comparisons, significantly lower values were seen for anterior white matter than for posterior regions in both groups, with more significant difference in the elderly. Thus, the present data demonstrate that, in terms of anisotropy values, the anterior white matter is more vulnerable to aging than posterior regions. This finding confirms the suggestion of an anterior-to-posterior gradient described previously. ${ }^{22-23}$
Studies on changes in subcortical white matter and corpus callosum with aging have been published by several international groups, although no reports were found in the national literature. These studies related to ageing, reported differential axonal loss and demyelination of the fibers that constitute the several tracts of subcortical white matter, including the corpus callosum, with changes affecting the anterior regions to a greater degree than the posterior region..$^{5,6,22,24-28}$ These results are comparable to those of the present study.

The associative subcortical white matter tracts establish the long intra-hemispheric connections, with information traveling between anterior and posterior regions of the hemispheres, while the corpus callosum is the main neocortical commissure, and forms most inter-hemispheric connections. ${ }^{1,26,29,30-32}$ These fiber systems participate in the large neural networks that support (bi)-hemispheric activities, and underpin the complex cognitive, behavioral, motor and sensory functions. The disruption of these networks may be related to impairment of neural integration through disconnection mechanisms, one of the proposed causes of cognitive changes seen in pathological states and ageing. ${ }^{10,12,29-30,33-34}$

Thus, it is conceivable that the subcortical white matter tract and corpus callosum damage that occurs predominantly in anterior regions in elderly subjects, as observed in the present and other studies, may be related to anterior disconnection manifestations. ${ }^{10,33-38}$ Considering their relation to the anterior high-level integrative regions, such disconnections are of importance in providing a structural basis for the vulnerability and eventual impairment of the complex executive function cognitive domain. ${ }^{24,37-45}$

Quantitative DTI-FA studies that assess structural agerelated changes may be help provide a better understanding of pathophysiological aspects of cognitive manifestations related to normal aging. Additionaly, such studies may 
serve as a standard for comparison with various structuralrelated brain disorders. ${ }^{7,21}$

\section{Conclusion}

The ageing process of the brain subcortical white matter and corpus callosum correlates with changes in anisotropy values. These changes may presently be revealed by quantitative DTI-FA, an in vivo marker of fiber integrity. DTI-FA appears to be the most sensitive imaging parameter for determining age-related white matter damage. Furthermore, the frontal regions seem to be more vulnerable to aging in comparison to posterior regions.

The brain regions of normal subjects studied (anterior and posterior subcortical white matter, associative and commissural) showed lower DTI-FA values in the anterior region (subcortical white matter and genu), but not in the posterior region (subcortical white matter and splenium) in the elderly compared to the young group. These findings highlight the vulnerability of the anterior region and reinforce the notion of an anterior-posterior gradient of fiber loss.

The subcortical white matter tracts participate in the constitution of the wide neural networks which form the basis of cognitive, behavioral, motor and sensory integration. Loss of integrity in the anterior segments of the studied fiber systems with ageing, represents a disconnection process that may underlie clinical manifestations found in the elderly subjects such as executive dysfunction.

Acknowledgements - The authors thank Luzinete N.O. Alvarenga for her editorial assistance.

\section{References}

1. Engelhardt E, Moreira DM. A substância branca cerebral: dissecção virtual dos principais feixes: tratografia. Rev Bras Neurol 2008;44(2):19-34.

2. Engelhardt E, Moreira DM. A substância branca cerebral: localização dos principais feixes com anisotropia fracionada direcional. Rev Bras Neurol 2008;44(4):19-34.

3. Mori S, Oishi K, Jiang H, et al. Stereotaxic white matter atlas based on diffusion tensor imaging in an ICBM template. Neuroimage 2008;40:570-582.

4. Assaf Y, Pasternak O. Diffusion tensor imaging (DTI)-based white matter mapping in brain research: a review. J Mol Neurosci 2008;34:51-61.

5. Hasan KM, Kamali A, Kramer LA, Papnicolaou AC, Fletcher JM, Ewing-Cobbs L. Diffusion tensor quantification of the human midsagittal corpus callosum subdivisions across the lifespan. Brain Res 2008;1227:52-67.

6. Sullivan EV, Pfefferbaum A. Diffusion tensor imaging and aging. Neurosci Biobehav Rev 2006;30:749-761.
7. Taylor WD, Hsu E, Krishnan KRR, MacFall JR. Diffusion tensor imaging: background, potential, and utility in psychiatric research. Biol Psychiatry 2004;55:201-207.

8. Alexander AL, Lee JE, Lazar M, Field AS. Diffusion tensor imaging of the brain. Neurotherapeutics 2007;4:316-329.

9. Mori S, Zhang J. Principles of diffusion tensor imaging and its applications to basic neuroscience research. Neuron 2006; 51:527-539.

10. Schiavone F, Charlton RA, Barrick TR, Morris RG, Markus HS. Imaging age-related cognitive decline: A comparison of diffusion tensor and magnetization transfer MRI. J Magn Reson Imaging 2009;29:23-30.

11. Hasan KM, Gupta RK, Santos RM, Wolinsky JS, Narayana PA. Diffusion tensor fractional anisotropy of the normalappearing seven segments of the corpus callosum in healthy adults and relapsing-remitting multiple sclerosis patients. J Magn Reson Imaging 2005;21:735-743.

12. O’Sullivan M, Summers PE, Jones DK, et al. Normal-appearing white matter in ischemic leukoaraiosis: A diffusion tensor MRI study. Neurology 2001;57:2307-2310.

13. Allen JS, Bruss J, Brown CK, Damasio H. Normal neuroanatomical variation due to age: The major lobes and a parcellation of the temporal region. Neurobiol Aging 2005;26:1245-1260.

14. Salthouse TA. When does age-related cognitive decline begin? Neurobiol Aging 2009;30:507-514.

15. Goldman WP and Morris JC. Evidence That Age-Associated Memory Impairment Is Not a Normal Variant of Aging. Alz Dis Ass Dis 2001;15:72-79.

16. Folstein MF, Folstein SE, McHugh PR. "Mini-mental state”. A practical method for grading the cognitive state of patients for the clinician. J Psychiatr Res 1975;12:189-198.

17. Hughes CP, Berg L, Danziger WL, et al. A new clinical scale for the staging of dementia. Br J Psychiatry 1982;140:566-572.

18. Hachinski VC, Iliff LD, Zilhka E, et al. Cerebral blood flow in dementia. Arch Neurol 1975;32:632-637.

19. Fazekas F, Chawluk JB, Alavi A, et al. MR signal abnormalities at $1.5 \mathrm{~T}$ in Alzheimer's dementia and normal aging. Am J Neuroradiol 1987;8:421-426.

20. Wakana S, Jiang H, Nagae-Poetscher LM, van Zijl PC, Mori S. Fiber tract-based atlas of human white matter anatomy. Radiology 2004;230:77-87.

21. VassarStats: Statistical Computation Web Site. Disponível em: $<$ http://faculty.vassar.edu/lowry/VassarStats.html $>$. Acessado em: jun. de 2008.

22. Head D, Buckner RL, Shimony JS, et al. Differential vulnerability of anterior white matter in nondemented aging with minimal acceleration in dementia of the Alzheimer type: evidence from diffusion tensor imaging. Cereb Cortex 2004;14:410-423.

23. O'Sullivan M, Morris RG, Huckstep B, Jones DK, Williams SC, Markus HS. Diffusion tensor MRI correlates with execu- 
tive dysfunction in patients with ischaemic leukoaraiosis. J Neurol Neurosurg Psychiatry 2004;75:441-447.

24. Abe O, Aoki S, Hayashi N, et al. Normal aging in the central nervous system: quantitative MR diffusion-tensor analysis. Neurobiol Aging 2002;23:433-441.

25. Chepuri NB, Yen YF, Burdette JH, Li H, Moody DM, Maldjian JA. Diffusion anisotropy in the corpus callosum. AJNR Am J Neuroradiol. 2002;23:803-808.

26. Ota M, Obata T, Akine Y, et al. Age-related degeneration of corpus callosum measured with diffusion tensor imaging. Neuroimage 2006;31:1445-1452.

27. Sullivan EV, Rohlfing T, Pfefferbaum A. Quantitative fiber tracking of lateral and interhemispheric white matter systems in normal aging: Relations to timed performance. Neurobiol Aging 2008 [in press].

28. Zahr NM, Rohlfing T, Pfefferbaum A, Sullivan EV. Problem solving, working memory, and motor correlates of association and commissural fiber bundles in normal aging: a quantitative fiber tracking study. Neuroimage 2009;44:1050-1062.

29. Doron KW, Gazzaniga MS. Neuroimaging techniques offer new perspectives on callosal transfer and interhemispheric communication. Cortex 2008;44:1023-1029.

30. Gazzaniga MS. Cerebral specialization and interhemispheric communication. Does the corpus callosum enable the human condition? Brain 2000;123:1293-1326.

31. Putnam MC, Wig GS, Grafton ST, et al. Structural Organization of the Corpus Callosum Predicts the Extent and Impact of Cortical Activity in the Nondominant Hemisphere. J Neurosci 2008;28:2912-2918.

32. Stephan KE, Marshall JC, Penny WD, et al. Interhemispheric Integration of Visual Processing during Task-Driven Lateralization. J Neurosci 2007;7:3512-3522.

33. Salat DH, Tuch DS, Greve DN, et al. Age-related alterations in white matter microstructure measured by diffusion tensor imaging, Neurobiol Aging 2005;26:1215-1227.
34. Sullivan EV, Adalsteinsson E, Pfefferbaum A. Selective agerelated degradation of anterior callosal fiber bundles quantified in vivo with fiber tracking. Cereb Cortex. 2006;16: 1030-1039.

35. Catani M, Ffytche DH. The rises and falls of disconnection syndromes. Brain 2005;128:2224-2239.

36. Catani M, Mesulam M. What is a disconnection syndrome? Cortex 2008;44:911-913.

37. Pfefferbaum A, Adalsteinsson E, Sullivan EV. Frontal circuitry degradation marks healthy adult aging: Evidence from diffusion tensor imaging. Neuroimage 2005;26:891-899.

38. O'Sullivan M, Jones DK, Summers PE, Morris RG, Williams SCR, Markus HS. Evidence for cortical "disconnection" as a mechanism of age-related cognitive decline. Neurology 2001; 57:632-638.

39. Andrews-Hanna JR, Snyder AZ, Vincent JL, et al. Disruption of large-scale brain systems in advanced aging, Neuron 2007; 56:924-935.

40. Badre D. Cognitive control, hierarchy, and the rostro-caudal organization of the frontal lobes, Trends Cogn Sci 2008;12: 193-200.

41. Charlton RA, Barrick TR, McIntyre DJ, et al. White matter damage on diffusion tensor imaging correlates with agerelated cognitive decline. Neurology 2006;66:217-222.

42. Masterman DL, Cummings JL. Frontal-subcortical circuits: the anatomic basis of executive, social and motivated behaviors. J Psychopharmacol 2007;11:107-114.

43. Salat DH, Tuch DS, Hevelone ND, et al. Age-related changes in prefrontal white matter measured by diffusion tensor imaging. Ann N Y Acad Sci 2005;1064:37-49.

44. Schmahmann JD, Pandya DN. Disconnection syndromes of basal ganglia, thalamus, and cerebrocerebellar systems. 7

45. Zhang YT, Zhang CY, Zhang J, Li W. Age-related changes of normal adult brain structure: analysed with diffusion tensor imaging. Chin Med J (Engl) 2005;118:1059-1065. 